\title{
Nested PCR detection of malaria directly using blood filter paper samples from epidemiological surveys
}

Peipei Li , Zhenjun Zhao ${ }^{1}$, Ying Wang ${ }^{2}$, Hua Xing ${ }^{3}$, Daniel M Parker ${ }^{4}$, Zhaoqing Yang ${ }^{5}$, Elizabeth Baum ${ }^{6}$, Wenli Li ${ }^{3}$, Jetsumon Sattabongkot ${ }^{7}$, Jeeraphat Sirichaisinthop ${ }^{8}$, Shuying Li ${ }^{1}$, Guiyun Yan ${ }^{6}$, Liwang Cui ${ }^{4^{*}}$ and Qi Fan ${ }^{1 *}$

\begin{abstract}
Background: Nested PCR is considered a sensitive and specific method for detecting malaria parasites and is especially useful in epidemiological surveys. However, the preparation of DNA templates for PCR is often time-consuming and costly.

Methods: A simplified PCR method was developed to directly use a small blood filter paper square $(2 \times 2 \mathrm{~mm})$ as the DNA template after treatment with saponin. This filter paper-based nested PCR method (FP-PCR) was compared to microscopy and standard nested PCR with DNA extracted by using a Qiagen DNA mini kit from filter paper blood spots of 204 febrile cases. The FP-PCR technique was further applied to evaluate malaria infections in 1,708 participants from cross-sectional epidemiological surveys conducted in Myanmar and Thailand.

Results: The FP-PCR method had a detection limit of $\sim 0.2$ parasites/ML blood, estimated using cultured Plasmodium falciparum parasites. With 204 field samples, the sensitivity of the FP-PCR method was comparable to that of the standard nested PCR method, which was significantly higher than that of microscopy. Application of the FP-PCR method in large cross-sectional studies conducted in Myanmar and Thailand detected 1.9\% (12/638) and 6.2\% $(66 / 1,070)$ asymptomatic Plasmodium infections, respectively, as compared to the detection rates of $1.3 \%(8 / 638)$ and $0.04 \%(4 / 1,070)$ by microscopy.

Conclusion: This FP-PCR method was much more sensitive than microscopy in detecting Plasmodium infections. It drastically increased the detection sensitivity of asymptomatic infections in cross-sectional surveys conducted in Thailand and Myanmar, suggesting that this FP-PCR method has a potential for future applications in malaria epidemiology studies.
\end{abstract}

Keywords: Malaria, PCR detection, Blood filter paper, Epidemiology, Sensitivity, Accuracy

\section{Background}

Malaria, causing approximately 660,000 deaths each year, remains a major global health problem [1]. In the last decade, with substantially increased funding and more effective management through long-lasting insecticidal nets, rapid diagnostic tests (RDTs) and artemisininbased combination therapy (ACT), malaria control has achieved encouraging results and malaria elimination

\footnotetext{
* Correspondence: luc2@psu.edu; fanqi2002@yahoo.com

${ }^{4}$ Department of Entomology, Pennsylvania State University, University Park, Pennsylvania, PA, USA

'Dalian Institute of Biotechnology, Dalian, Liaoning, China

Full list of author information is available at the end of the article
}

has attracted increasing attention. The elimination of malaria transmission requires enhanced surveillance and control efforts, which rely on rapid detection and effective treatment of infections. This is especially important with regard to asymptomatic parasite carriers, which could serve as important reservoirs for continued transmission $[2,3]$. Most national malaria control programmes in endemic countries have installed passive case detection (PCD), whereas some also conduct active case detection (ACD) at sentinel sites. Currently, malaria case detection depends heavily on microscopy and/or RDTs. However, both methods miss infections when parasite densities are low ( $<10$ parasites $/ \mu \mathrm{L})$ [4]. These submicroscopic 
infections are quite common in areas where malaria is seasonal and unstable $[3,5,6]$, and they, therefore, represent major challenges for malarial control and elimination programmes.

Compared with conventional microscopy or RDTs, molecular tools, such as PCR, are highly sensitive in detecting low-density infections and determining the parasite species [7]. Although PCR has limitations for use as a routine diagnostic method in clinical settings, it has been used extensively in malaria surveillance. For this purpose, samples can be pooled for DNA extraction and analysis to further reduce the cost and increase the throughput [8-10]. For PCR, a routinely used method for parasite DNA extraction from dried blood spots is the Chelex boiling method [11], which increases the chances of sample cross contamination when many samples are processed at the same time. In our experience, DNA samples obtained using the Chelex method tend to degrade faster than those obtained using the Qiagen kit after extended storage at $-20^{\circ} \mathrm{C}$. Alternatively, filter paper blood spots are directly used in PCR without extraction [12]. Yet, washing filter blood spots with warm water during this procedure may lead to the loss of parasite DNA. In this report, a procedure to include a saponin treatment step of filter paper blood samples for direct PCR analysis was developed. It was further validated for malaria surveillance using samples from $\mathrm{PCD}$ and cross-sectional studies conducted in western Thailand and north-east Myanmar.

\section{Methods}

\section{Study areas and sample collection}

This study was performed at study sites in northeast Myanmar and western Thailand, where malaria is characterized as hypoendemic and seasonal. The study areas have a predominance of Plasmodium falciparum and Plasmodium vivax infections. For method development and initial validation, samples from 204 randomly selected febrile patients (temperature $>37.5^{\circ} \mathrm{C}, 112$ males and 92 females, ages ranging from six months to 73 years) suspected of uncomplicated malaria at malaria clinics near Laiza township, Kachin State in north-east Myanmar were evaluated. This method was further applied to 1,708 samples collected from cross-sectional studies, including 638 participants recruited from 10 villages near Laiza township in May and August of 2011, and 1,070 samples collected in four border villages of Tha Song Yang district, Tak province, western Thailand in August and December of 2011 and May of 2012. Finger-prick blood samples were collected onto Whatman $3 \mathrm{M}$ filter paper, air dried, and individually placed in plastic bags for storage. Informed consent/assent was obtained from each participant. The study protocol was approved by institutional review boards at the Pennsylvania State
University, the Thai Ministry of Health, and Kunming Medical University, China.

\section{Microscopy}

Thick and thin blood films were prepared from peripheral blood. The slides were stained with Giemsa and screened for malaria parasites by microscopy with $(100 \times)$ oil immersion lens. Blood films were examined by two microscopists with at least five years of experience in malaria microscopy, who were blinded to each other's result. Smears were considered negative if no parasite was seen in $100 \times$ oil immersion fields in a thick blood film.

\section{Sample preparation}

For the standard PCR method, DNA was extracted from $\sim 100 \mu \mathrm{L}$ of dried blood on filter paper using the Qiagen DNA Mini Kit following the manufacturer's recommendation. DNA was eluted in $50 \mu \mathrm{L}$ of $\mathrm{H}_{2} \mathrm{O}$. For the direct PCR method from filter paper (FPPCR), a $2 \times 2 \mathrm{~mm}$ square was punched from blood spot into a $1.5 \mathrm{~mL}$ centrifuge tube. One hundred microlitres of $0.5 \%$ saponin in phosphate-buffered saline (PBS, $\mathrm{pH} 7.0$ ) were added and incubated at room temperature for $10 \mathrm{~min}$, and then were inverted a few times to mix. The samples were centrifuged at $13,000 \times \mathrm{g}$ for $1 \mathrm{~min}$, and the supernatant was removed and discarded. Then the filter papers were washed with $1 \mathrm{~mL}$ of PBS, briefly dried and used immediately for PCR.

\section{PCR}

A modified nested PCR amplification was performed as described previously based on small subunit rRNA gene [12-14]. For the primary standard PCR reaction, $2 \mu \mathrm{L}$ of genomic DNA were used in a $25 \mu \mathrm{L}$ reaction with outer primers rPLU5 and rPLU6 [15]. For the FP-PCR, the same $25 \mu \mathrm{L}$ reaction was prepared with DNA template replaced by the filter paper disk. PCR was done under the same cycle conditions, which included an initial denaturing period at $94^{\circ} \mathrm{C}$ for $4 \mathrm{~min}$ and 30 cycles of $94^{\circ} \mathrm{C}$ for $1 \mathrm{~min}, 55^{\circ} \mathrm{C}$ for $2 \mathrm{~min}$ and $72^{\circ} \mathrm{C}$ for $2 \mathrm{~min}$, and a final extension for $5 \mathrm{~min}$. Nested PCR was performed with $2 \mu \mathrm{L}$ of the primary PCR product and species-specific primers for the four human malaria species and Plasmodium knowlesi in separate reaction tubes. Thirty PCR cycles $\left(94^{\circ} \mathrm{C}\right.$ for $40 \mathrm{~s}, 58^{\circ} \mathrm{C}$ for $1 \mathrm{~min}$ and $72^{\circ} \mathrm{C}$ for $\left.2 \mathrm{~min}\right)$ were performed [13].

For blood filter samples collected during crosssectional studies, the primary FP-PCR was done using the same conditions with blood filter paper discs as DNA templates and outer primers rPLU1 and rPLU5. Because a small fraction of the blood filter samples were diagnosed for malaria, nested PCR was done using genusspecific primers rPLU3 and rPLU4 under the same cycle conditions except for the change of annealing temperature 
to $62^{\circ} \mathrm{C}$ [16]. For the PCR positive samples, nested PCR was performed using species-specific primers for the four human malaria species and $P$. knowlesi in separate reaction tubes.

All PCR products were separated in 1\% and 2\% agarose gels for primary and nested PCR, respectively. After staining with ethidium bromide, the gel was visualized under a UV light.

\section{Detection limit of the FP-PCR}

To determine the sensitivity of the FP-PCR, P. falciparum 3D7 parasites were cultured in type $\mathrm{O}^{+} \mathrm{RBCs}$ in complete medium supplemented with $10 \%$ human $\mathrm{AB}$ serum under an atmosphere of $90 \% \mathrm{~N}_{2} / 5 \% \mathrm{O}_{2} / 5 \% \mathrm{CO}_{2}$ [17]. Synchronization of parasite cultures with $5 \%$ sorbitol was performed as previously described [18]. Ring stage parasites at $2 \%$ parasitaemia were concentrated to $\sim 45 \%$ haematocrit. Two-fold serial dilutions were performed to the lowest parasitaemia of $1.7 \times 10^{-12} \%$ by adding an equal volume of uninfected RBCs at the same haematocrit. One hundred microlitres of each dilution were spotted on Whatman $3 \mathrm{M}$ filter paper, air-dried and stored at $-20^{\circ} \mathrm{C}$ until use. From each spot, ten $2 \times 2 \mathrm{~mm}$ squares were individually used for FP-PCR analysis as described above or the original filter paper blood PCR method [12]. Parasite density was estimated by using an $\mathrm{RBC}$ count of 5 million $/ \mu \mathrm{L}$ blood.

\section{Data analysis}

Diagnostic performance for each test was evaluated with the results of nested PCR method using DNA extracted from blood spots by using the Qiagen kit. Performance indices were the number of true positive (TP), the number of true negative (TN), the number of false positive (FP) and number of false negative (FN). Sensitivity was expressed as $\mathrm{TP} /(\mathrm{TP}+\mathrm{FN})$ and specificity as $\mathrm{TN} /$ $(\mathrm{TP}+\mathrm{FP})$. Accuracy of the tests were calculated as (TP/ $\mathrm{TN}) /$ number of all tests. Kappa statistics were used to compare the agreement against which might be expected by chance, with possible values ranging from 1 (perfect agreement) to -1 (complete disagreement) and 0 indicating agreement attributable to chance.

\section{Results}

\section{The FP-PCR method}

In order to avoid potential cross contamination due to heating during DNA preparation from filter paper blood [12], we evaluated a nested PCR method using $2 \times 2 \mathrm{~mm}$ squares of blood filter paper directly after simple saponin treatment and buffer washing. Saponin treatment lyses cholesterol-rich RBC membranes and subsequent buffer washing removes PCR inhibitors such as hemoglobin. To test the feasibility of this procedure, we first compared this FP-PCR method with the original filter paper blood PCR method [12] and standard PCR protocol using DNA isolated with the Qiagen kit. The blood filter paper was prepared from serial dilutions of $P$. falciparum laboratory culture with a known parasitemia. Under these experimental conditions, the lowest parasitaemia that consistently produced positive PCR result for the two filter paper methods was $3.8 \times 10^{-6} \%$, corresponding to $\sim 0.2$ parasites $/ \mu \mathrm{L}$ blood. In comparison, the lowest parasitaemia detected for the PCR using DNA prepared by the Qiagen kit was $3.1 \times 10^{-5} \%$, corresponding to $\sim 1.5$ parasites $/ \mu \mathrm{L}$.

\section{Validation of the FP-PCR method using field samples}

The suitability of the FP-PCR method for malaria surveillance was evaluated using 204 febrile cases showing malaria-like symptoms from a malaria clinic in northeastern Myanmar. The FP-PCR method was compared directly with microscopy and standard PCR method using DNA extracted with the Qiagen kit. Microscopic examination of blood films by two experienced microscopists detected malaria parasites in 169 patients, including 58 P. falciparum, 93 P. vivax, and 18 P. falciparum/ $P$. vivax mixed infections (Table 1 ). Compared with microscopy, both nested PCR methods displayed higher

Table 1 Comparison of diagnostic results from microscopy and two nested PCR results in 204 PCD cases

\begin{tabular}{|c|c|c|c|c|c|c|}
\hline \multirow[t]{2}{*}{ Method } & \multirow[t]{2}{*}{ Result } & \multicolumn{4}{|c|}{ Nested PCR (using DNA purified by kit) } & \multirow[t]{2}{*}{ Total } \\
\hline & & P. falciparum & P. vivax & Mix of $P f \& P v$ & Negative & \\
\hline \multirow[t]{4}{*}{ Microscopy } & P. falciparum & 45 & 2 & 10 & 1 & 58 \\
\hline & P. vivax & 4 & 74 & 14 & 1 & 93 \\
\hline & Mix of Pf \& $P V$ & 14 & 2 & 2 & 0 & 18 \\
\hline & Negative & 5 & 5 & 2 & 23 & 35 \\
\hline \multirow[t]{5}{*}{ Nested PCR (using blood filter papers) } & P. falciparum & 68 & 0 & 10 & 0 & 78 \\
\hline & P. vivax & 0 & 82 & 11 & 0 & 93 \\
\hline & Mix of $P f \& P V$ & 0 & 0 & 7 & 0 & 7 \\
\hline & Negative & 0 & 1 & 0 & 25 & 26 \\
\hline & Total & 68 & 83 & 28 & 25 & 204 \\
\hline
\end{tabular}


Table 2 Performance of microscopy and FP-PCR method in 204 PCD cases

\begin{tabular}{lccccc}
\hline $\begin{array}{l}\text { Method/ } \\
\text { Specimen }\end{array}$ & Category & Sensitivity (\%) & $\begin{array}{c}\text { Accuracy (\%) } \\
(\mathbf{n}=\mathbf{2 0 4})\end{array}$ & $\begin{array}{c}\text { Kappa } \\
(\mathbf{n}=\mathbf{2 0 4})\end{array}$ \\
\cline { 2 - 6 } Microscopy & P. falciparum & $74.0(65.7-82.2)$ & 176 samples exclude mix infected cases & 85.3 & 0.70 \\
& P. vivax & $82.9(75.2-90.5)$ & $91.6(85.9-97.2)$ & 81.4 & 0.63 \\
\hline FP-PCR & P. falciparum & $88.5(82.5-94.6)$ & $100.0(100.0-100.0)$ & 94.6 & 0.89 \\
& P. vivax & $90.1(84.0-96.2)$ & $98.8(96.6-100)$ & 94.6 & 0.89 \\
\hline
\end{tabular}

"Data are presented as percentage (95\% confidence interval; $\mathrm{Cl}$ ). The results from nested PCR with DNA prepared by the Qiagen kit were used as the gold standard.

sensitivities. Standard nested PCR using DNA prepared with the Qiagen kit detected 179 malaria cases infected with $P$. falciparum $(\mathrm{n}=68), P$. vivax $(\mathrm{n}=83)$, and both species $(\mathrm{n}=28)$ (Table 1$)$. Similarly, the FP-PCR method detected 178 malaria cases infected with $P$. falciparum $(\mathrm{n}=78), P . \operatorname{vivax}(\mathrm{n}=93)$ and both species $(\mathrm{n}=7)$ (Table 1). If nested PCR with kit prepared DNA was used as the gold standard, the sensitivity of microscopy for detection of $P$. falciparum and P. vivax was 74.0 and $82.9 \%$, respectively, whereas the sensitivity of the FP-PCR method for detecting $P$. falciparum and for $P$. vivax was increased to 88.5 and $90.1 \%$, respectively. Correspondingly, the test accuracy of microscopy for P. falciparum and $P$. vivax was $85.3 \%$ and $81.4 \%$ respectively, which was increased to $94.6 \%$ for both parasites by the FP-PCR method (Table 2). With clearly increased sensitivity, the standard PCR method improved the detection sensitivity and accuracy of mixed species infections. Although microscopy detected 18 mixed species infections, only two were confirmed by the standard PCR method. Somehow, the FP-PCR method was less sensitive in detecting mixed species infections. Of the 28 mixed infections detected by the standard PCR method, the FP-PCR method only confirmed 7 as mixed infections, whereas the remaining 21 were determined to be $10 P$. falciparum and $11 P$. vivax single infections.

\section{Applications of FP-PCR technique in epidemiological surveys}

The FP-PCR method was further validated using 1,708 filter paper blood samples collected from several crosssectional surveys. Of the 638 samples from northeastern Myanmar, microscopy detected eight malaria cases (two $P$. falciparum, three $P$. vivax and three $P$. falciparum/ $P$. vivax mixed infections). FP-PCR confirmed the two
$P$. falciparum and three $P$. vivax cases. For the three mixed infections, FP-PCR identified them as one P. falciparum single-species infections and two negative cases. In addition, FP-PCR detected an additional one P. falciparum and five $P$. vivax infections from the microscopynegative cases (Table 3 ).

Of the 1,070 samples from three cross-sectional studies in western Thailand, only four cases (one P. falciparum and three $P$. vivax) were initially identified by microscopy. In contrast, FP-PCR detected a total of 66 malaria infections (13 P. falciparum, 48 P. vivax, one Plasmodium malariae, and four mixed species infection by $P$. falciparum and P. vivax) (Table 3). The P. malariae case was verified by sequencing of the PCR product. It is worth to mention that a subset 217 Thai samples collected in May 2012 were detected by FP-PCR with a malaria infection rate of $13.8 \%$. This infection rate largely agreed with the results obtained by PCR using DNA prepared by the Qiagen kit using filter paper blood samples collected in the same village at the same time.

\section{Discussion}

Microscopy and RDTs both underestimate malaria parasite prevalence, especially for asymptomatic infections with a low parasitemia. Here a FP-PCR method for the detection of malaria parasites in dried blood filter paper was described. This PCR method uses a small square of blood filter paper directly as the source of parasite DNA, which significantly reduces the time and cost of DNA preparation. It incorporated a simple step of saponin treatment of the blood filter paper square in order to lyse the RBCs and remove potential inhibitors for PCR. While this FP-PCR method was similar in sensitivity to the original filter paper PCR method [12], the FP-PCR method does not require a heated step during DNA

Table 3 Performance of microscopy and FP-PCR technique in cross-sectional surveys

\begin{tabular}{cccccccccc}
\hline Sites & Methods & P. falciparum & P. vivax & P. falciparum + P. vivax & P. malariae & P. ovale & Negative & Total & Positive rate \\
\hline Myanmar & FP-PCR & 4 & 8 & 0 & 0 & 0 & 626 & 638 & $1.9 \%$ \\
& Microscopy & 2 & 3 & 3 & 0 & 0 & 630 & 638 & $1.3 \%$ \\
\hline \multirow{2}{*}{ Thailand } & FP-PCR & 13 & 48 & 4 & 0 & 0 & 0 & 1,004 & 1,070 \\
& Microscopy & 1 & 3 & 0.066 & 1,070 & $0.04 \%$ \\
\hline
\end{tabular}


extraction, thus reducing the chances of potential cross contamination. The detection limit of the FP-PCR method determined using cultured P. falciparum parasites was approximately 0.2 parasites $/ \mu \mathrm{L}$ blood, $\sim 50$ times more sensitive than the detection limit of $>10$ parasites/ $\mu \mathrm{L}$ blood of microscopy. Yet, the FP-PCR method underperformed on mixed species infections when compared with the Qiagen kit method using clinical samples. With parasite samples from PCD, the FP-PCR method was much more sensitive than microscopy. The simplified DNA preparation involved in the FP-PCR suggests a good potential for applications in epidemiological studies of malaria.

With a large sample collection of blood filter papers from cross-sectional surveys in the Thailand and Myanmar, the FP-PCR method was found to drastically increase the detection sensitivity over conventional microscopy, especially for asymptomatic infections. One of the current malaria management strategies at these sites focuses on timely treatment of malaria cases with appropriate anti-malarial drugs, aiming at reducing and eliminating malaria transmission from these active cases. However, the presence of large number of asymptomatic infections in the study population that went undetectable by microscopy suggests that treating the symptomatic cases alone will not completely stop malaria transmission. These asymptomatic malaria parasite carriers may serve as important sources of continued malaria transmission in these border regions. It underlines the significance of deploying more sensitive methods of parasite detection of the asymptomatic infections, which will enable the planning and execution of radical measures such as mass drug administration for malaria elimination.

\section{Conclusion}

A FP-PCR method for the detection of malaria parasites using a small square of blood filter paper directly as the source of parasite DNA was established. This method significantly reduces the time and cost of DNA preparation. It was much more sensitive than microscopy. The performance in cross-sectional surveys in the Thailand and Myanmar showed that the FP-PCR method drastically improved the detection of asymptomatic infections.

\section{Competing interests}

The authors declare that they have no competing interests.

\section{Authors' contributions}

$P L, Z Z, Y W, H X$ and $Z Y$ carried out the experimental work and data analysis. WL, DMP, ZY, EB, JS and JS participated in data analysis. PL performed manuscript writing. GY, LC and QF conceived the study and participated in the design of the study. All authors read and approved the final manuscript

\section{Acknowledgements}

This project was funded by the National Institute of Health (U19 Al089672).

\section{Author details}

'Dalian Institute of Biotechnology, Dalian, Liaoning, China. ${ }^{2}$ Institute of Tropical Medicine, Third Military Medical University, Chongqing, China. ${ }^{3}$ Dalian University of Technology, Dalian, Liaoning, China. ${ }^{4}$ Department of Entomology, Pennsylvania State University, University Park, Pennsylvania, PA, USA. ${ }^{5}$ Department of Pathogen Biology and Immunology, Kunming Medical University, Kunming, Yunnan, China. ${ }^{6}$ Program in Public Health, University of California, Irvine, CA, USA. ${ }^{7}$ Faculty of Tropical Medicine, Mahidol University, Bangkok 10400, Thailand. ${ }^{8}$ Vector Borne Disease Training Center, Pra Budhabat, Saraburi 18120, Thailand.

Received: 10 March 2014 Accepted: 1 May 2014 Published: 8 May 2014

\section{References}

1. WHO: World Malaria Report 2012. Geneva: World Health Organization; 2012.

2. Karl S, Gurarie D, Zimmerman PA, King CH, St Pierre TG, Davis TM: A submicroscopic gametocyte reservoir can sustain malaria transmission. PLoS One 2011, 6:e20805.

3. Okell LC, Bousema T, Griffin JT, Ouedraogo AL, Ghani AC, Drakeley CJ: Factors determining the occurrence of submicroscopic malaria infections and their relevance for control. Nat Commun 2012, 3:1237.

4. Harris I, Sharrock WW, Bain LM, Gray KA, Bobogare A, Boaz L, Lilley K, Krause D, Vallely A, Johnson ML, Gatton ML, Shanks GD, Cheng Q: A large proportion of asymptomatic Plasmodium infections with low and sub-microscopic parasite densities in the low transmission setting of Temotu Province, Solomon Islands: challenges for malaria diagnostics in an elimination setting. Malar J 2010, 9:254.

5. Ouedraogo AL, Bousema T, Schneider P, de Vlas SJ, Ilboudo-Sanogo E, Cuzin-Ouattara N, Nebie I, Roeffen W, Verhave JP, Luty AJ, Sauerwein R: Substantial contribution of submicroscopical Plasmodium falciparum gametocyte carriage to the infectious reservoir in an area of seasonal transmission. PloS One 2009, 4:e8410.

6. Steenkeste N, Rogers WO, Okell L, Jeanne I, Incardona S, Duval L, Chy S, Hewitt S, Chou M, Socheat D, Babin FX, Ariey F, Rogier C: Sub-microscopic malaria cases and mixed malaria infection in a remote area of high malaria endemicity in Rattanakiri province, Cambodia: implication for malaria elimination. Malar J 2010, 9:108.

7. Hawkes M, Kain KC: Advances in malaria diagnosis. Expert Rev Anti Infect Ther 2007, 5:485-495.

8. Hsiang MS, Lin M, Dokomajilar C, Kemere J, Pilcher CD, Dorsey G, Greenhouse B: PCR-based pooling of dried blood spots for detection of malaria parasites: optimization and application to a cohort of Ugandan children. J Clin Microbiol 2010, 48:3539-3543.

9. Taylor SM, Juliano JJ, Trottman PA, Griffin JB, Landis SH, Kitsa P, Tshefu AK, Meshnick SR: High-throughput pooling and real-time PCR-based strategy for malaria detection. J Clin Microbiol 2010, 48:512-519.

10. Congpuong K, Saejeng A, Sug-Aram R, Aruncharus S, Darakapong A, Meshnick SR, Satimai W: Mass blood survey for malaria: pooling and real-time PCR combined with expert microscopy in north-west Thailand. Malar J 2012, 11:288.

11. Plowe CV, Djimde A, Bouare M, Doumbo O, Wellems TE: Pyrimethamine and proguanil resistance-conferring mutations in Plasmodium falciparum dihydrofolate reductase: polymerase chain reaction methods for surveillance in Africa. Am J Trop Med Hyg 1995, 52:565-568.

12. Fuehrer HP, Fally MA, Habler VE, Starzengruber P, Swoboda P, Noedl H: Novel nested direct PCR technique for malaria diagnosis using filter paper samples. J Clin Microbiol 2011, 49:1628-1630.

13. Yan J, Li N, Wei X, Li P, Zhao Z, Wang L, Li S, Li X, Wang Y, Li S, Yang Z, Zheng B, Zhou G, Yan G, Cui L, Cao Y, Fan Q: Performance of two rapid diagnostic tests for malaria diagnosis at the China-Myanmar border area. Malar J 2013, 12:73.

14. Buppan P, Putaporntip C, Pattanawong U, Seethamchai S, Jongwutiwes S: Comparative detection of Plasmodium vivax and Plasmodium falciparum DNA in saliva and urine samples from symptomatic malaria patients in a low endemic area. Malar J 2010, 9:72.

15. Snounou G, Viriyakosol S, Zhu XP, Jarra W, Pinheiro L, do Rosario VE, Thaithong S, Brown KN: High sensitivity of detection of human malaria parasites by the use of nested polymerase chain reaction. Mol Biochem Parasitol 1993, 61:315-320. 
16. Singh B, Bobogare A, Cox-Singh J, Snounou G, Abdullah MS, Rahman HA: A genus- and species-specific nested polymerase chain reaction malaria detection assay for epidemiologic studies. Am J Trop Med Hyg 1999, 60:687-692.

17. Trager $W$, Jensen JB: Human malaria parasites in continuous culture. Science 1976, 193:673-675.

18. Lambros C, Vanderberg JP: Synchronization of Plasmodium falciparum erythrocytic stages in culture. J Parasitol 1979, 65:418-420

doi:10.1186/1475-2875-13-175

Cite this article as: $L i$ et al:: Nested PCR detection of malaria directly using blood filter paper samples from epidemiological surveys. Malaria Journal 2014 13:175.

\section{Submit your next manuscript to BioMed Central and take full advantage of:}

- Convenient online submission

- Thorough peer review

- No space constraints or color figure charges

- Immediate publication on acceptance

- Inclusion in PubMed, CAS, Scopus and Google Scholar

- Research which is freely available for redistribution 